\title{
Design and Control of an Integrated Toluene-Aniline Production Plant a Preliminary Study
}

\author{
Ahtesham Javaid and Costin S. Bildea
}

\begin{abstract}
The scope of this research is to emphasize the importance, possibility and benefits about the coupling of exothermic and endothermic reactions. Coupling could be hydration with dehydration, oxidation with reduction and hydrogenation with dehydrogenation. Nonlinear analysis of reactor-separation-recycle shows difficulties in controlling integrated plants when un-reacted reactant is recycled. As a case study simultaneous hydrogenation of Nitrobenzene to Aniline with dehydrogenation of Methyl-cyclohexane to Toluene is investigated. Instead of multi-tubular reactor, the coupled reaction is carried out in a single tube adiabatic reactor, therefore the complex set-up for hydrogenation and large amount of hydrogen to avoid reaction run-away are no longer required. The steady state and dynamic state behaviour of an integrated plant is analysed using AspenPlus and AspenDynamics respectively. On implementing plantwide control structure the change in production rate is studied. The new system is simpler, stable and robust to feed disturbances. The results obtained here are also applicable to other chemical processes of practical relevance.
\end{abstract}

Index Terms-Aspen, exothermic and endothermic reactions, process integration, reactor-separation-recycle, parametric sensitivity.

\section{INTRODUCTION}

Process integration is a method in process technology which can reduce material and energy consumption by combining several processes in one system [1]. The concept of process integration is not new but it has started back in 1970's [2]. In recent times several researchers worked on the multi-functional reactors and studied the possibility of coupling exothermic and endothermic reactions by performing the reactions in the same unit. In this way, the heat produced by exothermic reactions can drive the endothermic reaction. This leads to improved thermal efficiency and for reversible reactions, can lead to increased equilibrium conversion and reaction rate due to equilibrium displacement [3]. As a result, simpler reactor of reduced size and significant energy savings can be achieved. In practice, energy savings and reduced reactor investment must outweigh the cost of required additional separation

Manuscript received February 1, 2017; revised May 5, 2017.

Ahtesham Javaid is with Pakistan Atomic Energy Commission, P. O. Box. 1114, Islamabad, Pakistan (e-mail: ahteshamjavaid@hotmail.com).

Costin S. Bildea is with the Department of Chemical and Biochemical Engineering, University Politehnica of Bucharest, Romania. units [4].

\section{A. The Evolution of Reactions Coupling}

The trend of publications on coupling of exothermic and endothermic reactions spans over the years from 1994 to 2011 [5]. Although some work has been done before these years, the real intensity in this field is seen since 1994 [6]. Broadly speaking the reactors used for coupling processes can be categorized in three types; regenerative, recuperative and direct. In recuperative coupling, exothermic and endothermic reactions are spatially segregated in the reactor with heat transfer occurring through the wall [7]. On the other hand, in the direct and regenerative mode of coupling the same catalytic bed is used to conduct both the exothermic and endothermic reactions. Mixing of the endothermic reactants with exothermic reactants or other components, designated as 'direct coupling' can eliminate the need for heat exchange and can strongly reduce or completely avoid catalyst deactivation [8]. Direct coupled reactor is the simplest and cheaper one, which is used in this study. The detailed comaprison among different schemes of coupling are given elsewhere [5]. Some guidelines regarding effective coupling of exothermic and endothermic reactions for better results and linear temperature profiles are provided in the study [6].

\section{B. Types of Thermal Reactors}

\section{1) Direct coupling}

In direct coupling two or more reactions occur simultaneously in the same reaction zone. As a result the material and energy is interchanged directly in the reaction mixture. However, there are some limitations for carrying on direct coupling e.g. as both reactions are carried out in the same catalytic bed so both catalysts of reactions should be in the same situation of temperature and pressure. Direct coupling reactor is furthure classified into simultaneous direct coupling adiabatic reactor (SIMDCAR) that favours both the exothermic and endothermic reaction and it is made of uniformly mixed exothermic and endothermic catalysts, and sequential direct coupling adiabatic reactor (SEQDCAR) having an alternating exothermic and endothermic catalytic bed as two different catalysts are not mixed in this reactor.

\section{2) Regenerative reactor}

In regenerative reactor, reactions are conducted in same reaction zone but only one reaction is occurring at one time, so by storing and discharge cycles, energy and material is interchanged. Reverse flow reactor is generally suitable for the integration of several process steps. The main advantages of this type of reactor are direct heat supply and efficient heat recovery. They are well suited for weakly 
exothermic reactions such as the catalytic purification of exhaust streams contaminated by volatile organic compounds [3]. Various investigators have studied reverse flow reactors and have concluded that one of the key issues is the development of hot spots that can damage the catalyst and the reactor walls.

\section{3) Recuperative coupling}

In this type of coupling both the reactions are occurring simultaneously but are separated physically either by separation wall or membrane. The energy interchange is predictable through the wall or membrane but material interchange is only possible by permeation through membrane. Recuperative reactors can be operated cocurrently or counter currently. Figures of all types of coupling reactors are shown in Fig. 1.

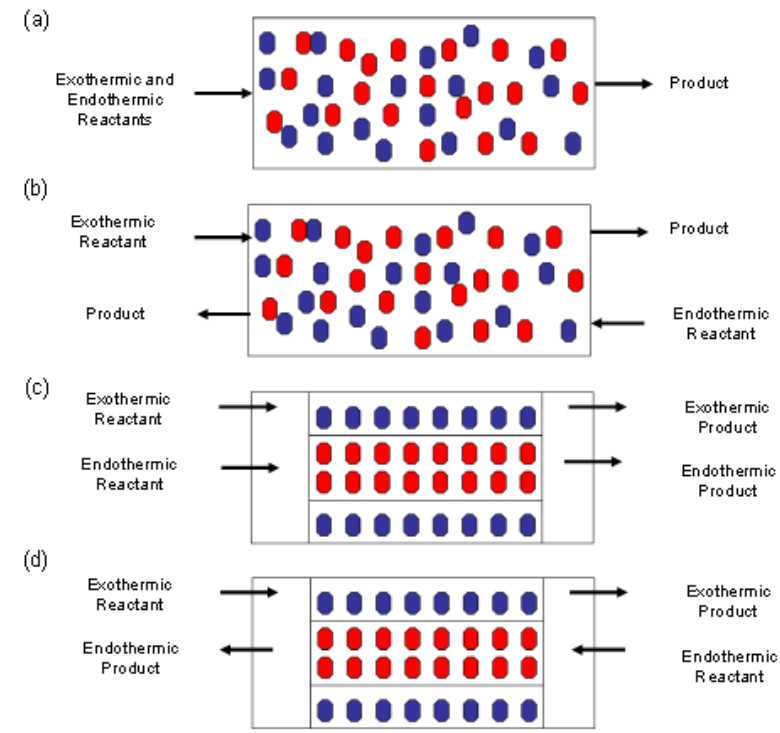

Fig. 1. Reactors for coupling of reactions: (a) Direct (b) Regenerative (c \& d) Recuperative Co and counter current.

\section{Reactor-separation-recycle}

Despite the availability of comprehensive literature on exothermic and endothermic reactions system, the previous studies are focused only on stand-alone reactor. The effect of implementing reaction coupling in plantwide systems has addressed in few studies [4], [9], [10]. The steady state behaviour of plantwide system for following scheme was investigated [4], [9] assuming constant reactor inlet temperature to rule out the possibility of energy feedback effects.

The results obtained from their studies are applicable to large class of chemical processes, where heat required to perform endothermic reactions are supplied by secondary exothermic reactions. The by-product in one reaction may also be used as a reactant in second reaction. Utilization of both material and energy could be done through efficient coupling. Typical reactor-separation-recycle system is shown in Fig. 2.

Due to recycling of un-reacted reactant the interaction between the reactor and separation section leads to complex behaviour [4], [9], [10]. To avoid complex nonlinearities, fix the flow rates of both reactants if they are recycled separately, and when the reactants are recycled together fix the flow rate of at least one reactant [10]. The details of plantwide control structures to overcome non-linearity and unfeasibility are given elsewhere [4], [9], [10]. Behaviour of integrated systems is analysed in few studies [11]-[14] and found this new process intensification technique feasible and beneficial.

$$
\begin{array}{ll}
A \stackrel{k_{1}}{\longrightarrow} R+Q & r_{A}=k_{1} w_{A} \Delta \mathrm{H}>0 \\
B+Q \stackrel{k_{2}}{\longrightarrow} P & r_{B}=k_{2} w_{B} w_{Q} \Delta \mathrm{H}<0
\end{array}
$$

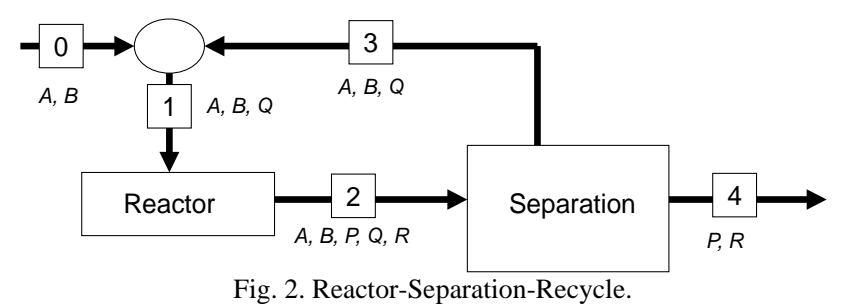

\section{INTEGRATED SYSTEM}

Aniline is one of the significant chemicals which is used for the manufacturing of many important chemicals, e.g. cyclo-hexylamine, benzoquinone and alkylaniline etc. It is usually manufactured by the hydrogenation of nitrobenzene at $300-475{ }^{\circ} \mathrm{C}$ in fixed bed reactors $(\Delta \mathrm{H}=-443.0$ $\mathrm{KJ} / \mathrm{mole}$ ). Because of highly exothermic reactions a cooled multi-tubular reactor is used, which is expensive due to its complexity and cost of cooling. In addition to the larger heat area, very large hydrogen to nitrobenzene ratio (about $100: 1)$ is needed, still tight temperature control is necessary in order to avoid reaction run-away.

$$
\begin{array}{cc}
\mathrm{C}_{6} \mathrm{H}_{5}-\mathrm{NO}_{2} & +3 \mathrm{H}_{2} \\
\mathrm{NB} & \rightarrow \mathrm{C}_{6} \mathrm{H}_{5}-\mathrm{NH}_{2}+2 \mathrm{H}_{2} \mathrm{O} \\
\mathrm{AN}
\end{array}
$$

On the other hand, a large amount of energy $(\Delta H=205.3$ $\mathrm{KJ} / \mathrm{mole}$ ) is required for endothermic dehydrogenation of methyl-cyclohexane (MCH) to toluene (TOL).

$$
\begin{array}{cc}
\mathrm{C}_{6} \mathrm{H}_{11}-\mathrm{CH}_{3} & \rightarrow \mathrm{C}_{6} \mathrm{H}_{5}-\mathrm{CH}_{3}+3 \mathrm{H}_{2} \\
\mathrm{MCH} & \text { TOL }
\end{array}
$$

Instead of operating two independent systems for the production of Toluene and Aniline, both reactions can be carried out simultaneously in a single tube adiabatic reactor. The proposed coupled reaction is shown in equation 5 .

$$
\mathrm{C}_{6} \mathrm{H}_{11}-\mathrm{CH}_{3}+\mathrm{C}_{6} \mathrm{H}_{5}-\mathrm{NO}_{2} \rightarrow \mathrm{C}_{6} \mathrm{H}_{5}-\mathrm{CH}_{3}+\mathrm{C}_{6} \mathrm{H}_{5}-\mathrm{NH}_{2}+2 \mathrm{H}_{2} \mathrm{O}
$$

As a result the complex set-up for the hydrogenation reactor is simplified and eliminating the requirement of large hydrogen recycle. The nonlinearity of the whole system is evaluated when recycle stream is incorporated into the system.

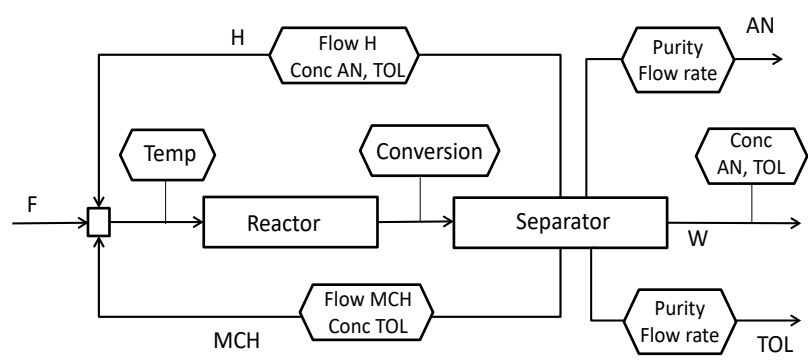

Fig. 3. Flow structure of an integrated plant. 


\section{A. Initial Data}

The design objective is to produce TOL and AN simultaneously of high purity in an integrated system. The flowsheet structure is given in Fig. 3. The feed stream (F) consists of hydrogen $(\mathrm{H})$, methyl-cyclohexane $(\mathrm{MCH})$ and nitrobenzene (NB). The reaction is performed in an adiabatic single tube plug-flow reactor. Heat exchanger is used to keep the reactants at reaction temperature. Boiling point differences among the products are the basis for designing of separation section. Hydrogen is separated from mixture by liquid-vapour separation and recycled. First distillation column separate aniline from rest of the mixture and second distillation is carried out to separate toluene.

\section{B. Kinetics}

The reaction kinetics used in the simulation is taken from the literature. Copper-nickel catalyst is considered for aniline production and alumina catalyst for $\mathrm{MCH}$ dehydrogenation. The following expressions were used: Aniline production [15]:

$$
\begin{gathered}
r_{1}=k_{2} \cdot p_{N B}^{0.5} \cdot p_{H_{2}}^{0.5} \\
k=0.114 \exp \left(-\frac{8323}{T}\right) \quad \mathrm{kmol} \times \mathrm{m}^{-3} \times \mathrm{s}^{-1} \times \mathrm{Pa}^{-1}
\end{gathered}
$$

MCH dehydrogenation [16]:

$$
\begin{gathered}
r_{1}=k_{1} \cdot p_{M C H} \\
k_{1}=3.07 \times 10^{13} \exp \left(\frac{-26539}{T}\right) \mathrm{kmol} \times \mathrm{m}^{-3} \times \mathrm{s}^{-1} \times \mathrm{Pa}^{-1}
\end{gathered}
$$

\section{INTEGRATED PLANT}

\section{A. Reactor}

Aspen Plus [17] simulator is used to study the behaviour of an integrated plant. Reactants are mixed and brought to reaction temperature, i.e. $300{ }^{\circ} \mathrm{C}$. Both reactions take place in a single tube adiabatic reactor having $1.5 \mathrm{~m}$ diameter and $4 \mathrm{~m}$ length. The conversion of nitrobenzene to Aniline and $\mathrm{MCH}$ to Toluene is $97 \%$ and $76 \%$, respectively. Temperature and molar profiles along the reactor length is given in Fig. 4. The uniform temperature distribution resists the catalyst deactivation.
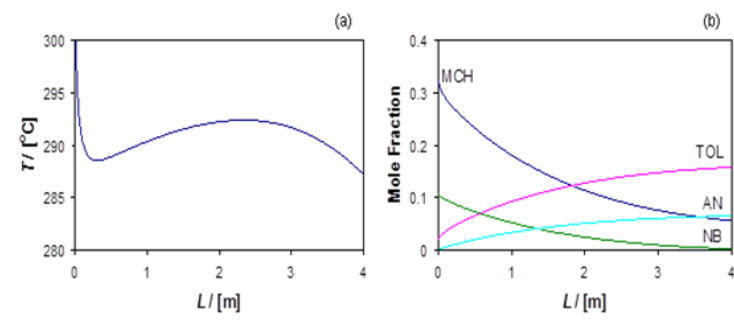

Fig. 4. Reactor profiles: (a) temperature (b) molarNB.

\section{Parametric study}

Parametric study is performed to check the robustness of the reactor. The reactor is operated on two different temperatures other than normal operating temperature. Linear and symmetrical temprature profiles are obtained which emphasize the stability of the reactor. Similar results ae obtained by varying Hydrogen to NB ratio. Profiles are shown in Fig. 5.
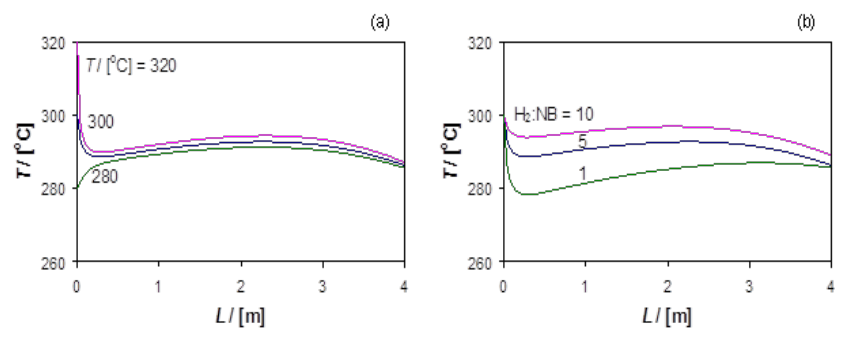

Fig. 5. Reactor profiles: (a) temperature (b) hydrogen.

\section{B. Flowsheet Description}

Reactants (Methyl-cyclohexane-60 kmol/h, nitrobenzene$20 \mathrm{kmol} / \mathrm{h}$ and hydrogen-100 kmol/h) are mixed and brought to reaction temperature $\left(300^{\circ} \mathrm{C}\right)$. The reactor outlet is cooled to $20{ }^{\circ} \mathrm{C}$, and vapor-liquid-liquid separation is performed. The hydrogen is recycled, while the organic phase is separated, in two distillation columns. First column, operated at 1 bar with 20 stages, separates the aniline from the rest of mixture. About 99.5\% aniline is recovered as a bottom product at the rate of $19.4 \mathrm{kmol} / \mathrm{h}$ with $97 \%$ purity. From the top, liquid distillate (MCH and TOL) is obtained and fed to second distillation column which is operated at 0.5 bar, having 40 stages. Toluene is obtained as a bottom product at the rate of $43 \mathrm{kmol} / \mathrm{h}$ with purity $>99 \%$. From the top, un-reacted $\mathrm{MCH}$ with little amount of impurities is obtained as liquid distillate and is recycled. Flowsheet and plantwide diagram is given in Fig. 6 and detail of process streams are provided in Table I.

\section{Plantwide Control}

The control strategy fixes the reactor-inlet flow of methyl-cyclohexane, hydrogen and nitrobenzene. The advantage of this control structure is that the production rate can be achieved by changing feed flow rates. A unique steady state exists for different inlet flow values. The control of heater, cooler and three phase separator is standard. The temperature of reactor-outlet stream is controlled by the cooling duty. Vapour-liquid-liquid separator has pressure controller to control vapour pressure, two liquid level controllers to control organic and aqueous phases. Control of the distillation column is standard: condenser duty controls the pressure, distillate and bottoms flow rates control the levels in the reflux drum and column sump. Tray temperature in the column is controlled by reboiler duty and product purity is ensured by controlling bottom temperature.

The controllers were chosen as PI and were tuned by the direct-synthesis method. The appropriate ranges of the controlled and manipulated variable were specified, and controller gain was set to $1 \% / \%$. The integral time was set equal to an estimated time constant of the process, i.e. 20 minutes for temperature, 12 minutes for pressure and 60 minutes for level control.

\section{Dynamics}

After analyzing the integrated system in steady state, the effect of combined feed ( $\mathrm{MCH}$ and $\mathrm{NB}$ ) disturbances is studied in dynamic state using Aspen Dynamics [18]. The 
change in feed rates is followed by change in TOL and AN production rate, while purity remains high. The result of dynamics simulation is shown in Fig. 7. It has been observed that the normal operating point is stable, and if the system is disturbed, it achieves a new steady state, which indicates the robustness of an integrated plant.

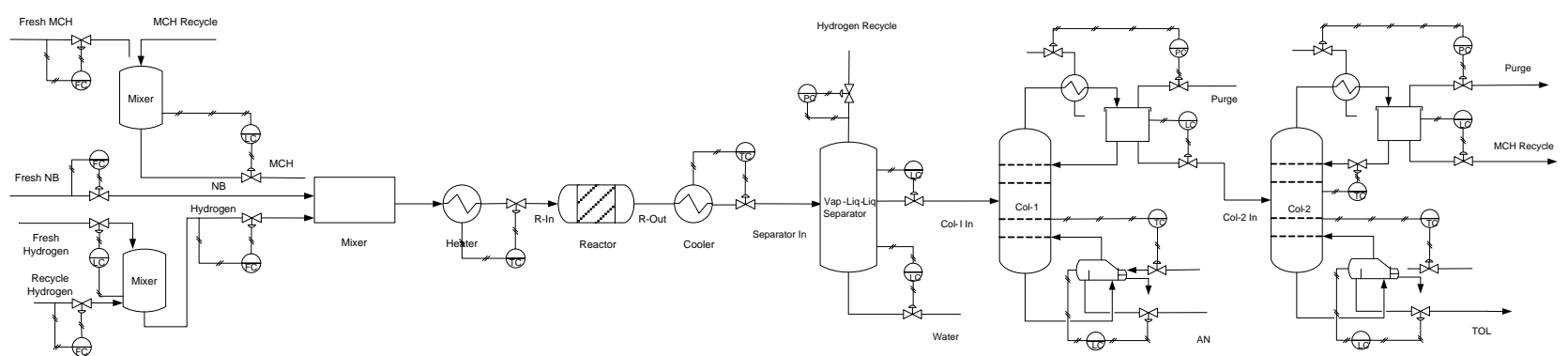

Fig. 6. Flowsheet and plantwide control.

TABLE II: STREAM TABLE

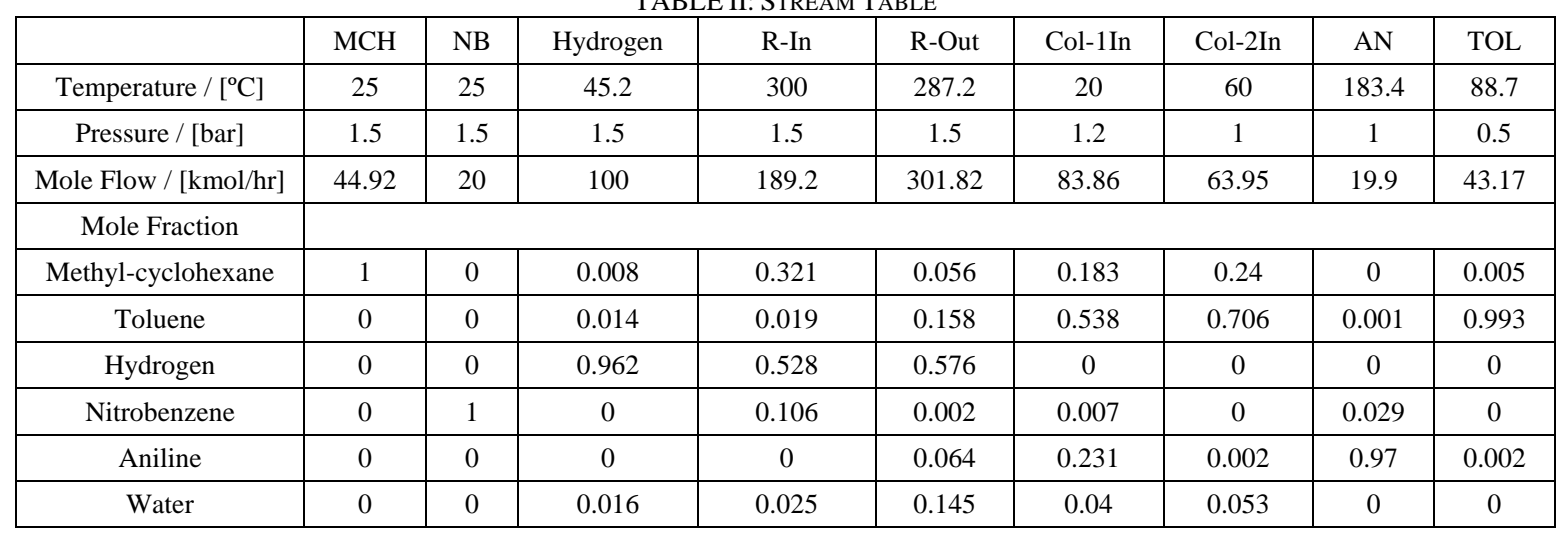
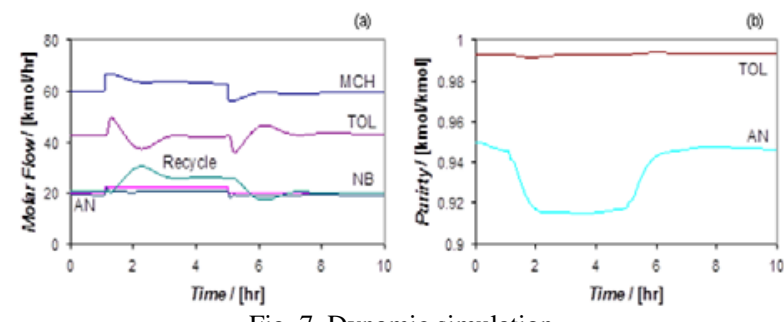

Fig. 7. Dynamic simulation.

\section{CONCLUSIONS}

Coupling of exothermic and endothermic reactions is one of the methods for process intensification in which both material and energy can be utilized. Incorporating both processes in a coupled unit can reduce the size and complexity of an equipment. An attempt has been made to prove the significance of this new field by considering direct mode of coupling. The behaviour of integrated plants where components are recycled is different from standalone reactors, and recycling adds non-linearity to the system. Integrated Toulene-Aniline production is feasible with the benefits of simpler reactor and less hydrogen requirement. The new system is less sensitive to feed temperature and hydrogen to NB ratio.

The complexity of plant is reduced by fixing the inlet flow of MCH, NB and Hydrogen. The robusteness of the integrated plant is checked in dynamic mode and found new coupled system controllable, allowing for changes in production rate while keeping high products purity.

\section{REFERENCES}

[1] F. Friedler, "Process integration, modelling and optimisation for energy saving and pollution reduction,” Appl. Therm. Eng., vol. 30, p. 2270, 2010.
[2] R. Smith, "State of the art in process integration,"Appl. Therm. Eng., vol. 20, pp. 1337-1345, 2000.

[3] G. Towler and S. Lynn, "Novel applications of reaction coupling: Use of carbon dioxide to shift the equilibrium of dehydrogenation reactions,” Chem. Eng. Sci., vol. 16, pp. 2585-2591, 1994.

[4] P. Altimari and C. S. Bildea, "Coupling exothermic and endothermic reactions in plug-flow reactor-separation-recycle systems," Ind. Eng. Chem. Res., vol. 47, pp. 6685-6697, 2008.

[5] M. R. Rahimpour, M. R. Dehnavi, F. Alalhgholipour, D. Iranshahi, and S. M. Jokar, Appl. Energy, pp. 99-496, 2012.

[6] R. C. Ramaswamy, Ph.D. Thesis, Sever Institute of Washington University, Saint Louis, USA, 2006.

[7] M. Zanfir and A. Gavriilidis, "Catalytic combustion assisted methane steam reforming in a catalytic plate reactor,”Chem. Eng. Sci., vol. 58, pp. 3947-3960, 2003.

[8] M. S. Kulkarni, Ph.D. Thesis, Sever Institute of Washington University, Saint Louis, USA, 1996.

[9] P. Altimari and C. S. Bildea, "Integrated design and control of plantwide systems coupling exothermic and endothermic reactions," Comput. Chem. Eng., vol. 33, pp. 911-923, 2009.

[10] K. Steur, C. S. Bildea, P. Altimari, and A. C. Dimian, "Integrated design and control of plantwide systems coupling exothermic and endothermic reactions,” Comput. Chem. Eng., vol. 33, p. 628, 2009.

[11] P. Octavian, V. van der Last, C. S. Bildea, and P. Altimari, "Design and control of integrated styrene-aniline production plant," Chemical Product and Process Modeling, vol. 4, no. 5, Article 19, 2009.

[12] A. Javaid and C. S. Bildea, "Design and control of an integrated 1,4butanediol dehydrogenation and furfural hydrogenation plant,” Chem. Eng. Technol., vol. 37, no. 9, pp. 1515-1524, 2014.

[13] A. Javaid and C. S. Bildea, "Design and control of Di n-Pentyl ether process,” Period. Polyteh. Chem. Engineering, vol. 59, no. 2, p. 165, 2015.

[14] A. Javaid and C. S. Bildea, "Integrated process for $\gamma$-butyrolactone production,” UPB Scientific Bulletin, vol. 76, no. 3, pp. 33-42, 2014.

[15] D. N. Rihani, T. K. Narayanan, and L. K. Doraiswamy, "Kinetics of catalytic vapor-phase hydrogenation of nitrobenzene to aniline,” Ind. Eng. Chem. Proc. Des. Dev., vol. 4, pp. 403-410, 1965.

[16] G. Maria, A. W. Marin, S. Muller, and E. Newson, "Modelling and scaleup of the kinetics with deactivation of methylcyclohexane dehydrogenation for hydrogen energy storage,” Chem. Eng. Sci., vol. 51, no. 11, pp. 2891-2896, 1996.

[17] ASPENTECH, “Aspen plus getting started building and running a process model,” ASPEN Technology, Burlington, 2010. 
[18] ASPENTECH, “Aspen dynamics user guide,” ASPEN Technology, Burlington, 2009.

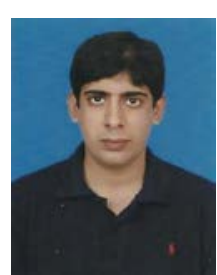

Ahtesham Javaid was born at Multan on August 14, 1983. He got his bachelor degree in chemical engineering in 2005 and master degree in process engineering in 2007. He completed his doctorate in 2014, from University Politehnica of Bucharest. His topic of research was "Design and control of chemical plants coupling of exothermic and endothermic reaction".

He started his career as a junior engineer in 2007 in a Public Sector Organization and deputed in Research and Development division. He got promoted to a senior engineer in 2009 and is currently working there. He has been involved in designing, commissioning and operation of chemical plants of various natures. He presented his research work in international conferences and published articles in well reputed journals.

Mr. Javaid is a member of Pakistan Engineering Council (PEC), International Association of Engineers (IAENGG), Pakistan Institute of Chemical Engineers (PICHE), Pakistan Society of Chemical Engineers (SChE) and Pakistan Nuclear Society (PNS). He has received fellowship from Pakistan Atomic Energy Commission for his master studies and got cultural exchange scholarship from Ministry of Education, Pakistan for $\mathrm{PhD}$ studies 